\begin{tabular}{|c|l|}
\hline Title & $\begin{array}{l}\text { Relationship between eyed-egg percentage and levels of cortisol and thy roid hormone in masu sal mon Oncorhynchus } \\
\text { masou }\end{array}$ \\
\hline Author(s) & Mingist, M.; Kitani, T.; Koide, N.; U eda, H. \\
\hline Citation & $\begin{array}{l}\text { Journal of Fish Biology, 70(4), 1045-1056 } \\
\text { https://doi.org/L0.1111j.1095-8649.2007.01362.x }\end{array}$ \\
\hline Issue Date & 2007-04 \\
\hline Doc URL & http://hdl.handle.net/2115/39885 \\
\hline Rights & The definitive version is available at www.blackwellsynergy.com \\
\hline Type & article (author version) \\
\hline File Information & ueda_JFB70.pdf \\
\hline
\end{tabular}

Instructions for use 


\title{
Relationship between eyed-egg percentage and levels of cortisol and thyroid hormone in masu salmon
}

\section{Oncorhynchus masou}

Running headline: EYED EGGS AND CORTISOL IN MASU SALMON

\section{MINGIST ${ }^{\dagger *}$, T. KITANI $^{\dagger}$, N. KOIDE ${ }^{\S}$ AND H. UEDA $^{\dagger \uparrow}$}

\author{
${ }^{\dagger}$ Division of Marine Biosciences, Graduate School of Fisheries Science, Hokkaido \\ University, Sapporo, Hokkaido 060-0809, Japan, ${ }^{\S}$ Hokkaido Fish Hatchery, Eniwa, \\ Hokkaido 061-1433, Japan, "Field Science Center for Northern Biosphere, Hokkaido \\ University, Sapporo, Hokkaido 060-0809, Japan
}

*Author to whom correspondence should be addressed. Tel. and Fax: +81-11-706-2598; email: minmar@fsc.hokudai.ac.jp 
This study investigated a possible cause of the low eyed-egg percentage that has occurred recently in pond-reared masu salmon Oncorhynchus masou, at the Kumaishi Fish Hatchery Station, Hokkaido, Japan. Serum cortisol levels of masu salmon during the spawning period were compared between individuals from Kumaishi and those from another station (Mori). Cortisol, thyroxine $\left(\mathrm{T}_{4}\right)$ and triiodothyronine $\left(\mathrm{T}_{3}\right)$ hormones were also measured in eyed eggs and their levels were compared to the eyed-egg percentage. Serum cortisol levels were significantly higher at Kumaishi than at Mori. There was a good relationship between serum cortisol and fertilized eggs cortisol levels. As cortisol levels in both ovulated females and in the eyed eggs increased, the eyed-egg percentage decreased, indicating a highly significant negative relationship between cortisol levels and eyed-egg percentage. In contrast, as the $T_{3}$ and $T_{4}$ levels in eyed eggs increased, the eyed-egg percentage increased. The consistently high cortisol level in serum and eyed eggs observed at Kumaishi may have had a significant effect in lowering the eyed-egg percentage.

Key words: cortisol; thyroid hormones; eyed-egg percentage; masu salmon. 


\section{INTRODUCTION}

Survival of fertilized eggs to the eyed egg stage is critical for hatchery programs to be successful. Incubation of poor quality eggs could lead to heavy losses at the eyed and latter stages of development. Variations in egg quality leading to variable post fertilization success are well demonstrated in fish, including Atlantic cod Gadus morhua (Kjorsvik, 1994), gilthead seabream Sparus aurata (Fernandez-Palacios et al., 1997), and rainbow trout Oncorhynchus mykiss (Bromage et al., 1992). Many factors are thought to affect the quality and survival of eggs, including nutrition, genetics, stress, health status, water temperature, and time after ovulation (Schreck et al., 2001).

In intensive rearing facilities, fish are often subjected to multiple stressors such as pollutants, temperature extremes, handling, transportation, and social interactions, which could result in adaptive or maladaptive stress responses (Davis et al., 2002; Acerete et al., 2004). In teleosts, the hypothalamic-pituitary-interrenal (HPI) axis is activated by stressors, and consists of a hormone cascade culminating in the release of cortisol from the interrenals into the blood stream (Rivier \& Rivest, 1991). Stress-induced cortisol release affects the overall metabolic system, including the immune response system, and may increase the susceptibility of the fish to diseases (Harris \& Bird, 2000; Davis et al., 2002). Elevated cortisol has also been linked with decline in body size, gonadosomatic index, egg size and gamete quality (Foo \& Lam, 1993a; Kime \& Nash, 1999).

Significant amounts of testosterone $(T)$, estradiol-17 $\beta\left(E_{2}\right)$, cortisol, thyroxine $\left(T_{4}\right)$ and triiodothyronine $\left(T_{3}\right)$ are consistently found in freshly ovulated eggs of teleosts (Tagawa et al., 1990; Deane \& Woo, 2003). Treatment of developing fish with $\mathrm{T}_{3}$ and $\mathrm{T}_{4}$ hormones induces earlier development and accelerates yolk absorption, growth and morphological 
differentiation (Leatherland, 1982). However, the physiological significance of these hormones on developing embryos is still unknown.

During recent years, low numbers of eyed-eggs or eyed-embryos in pond-reared masu salmon Oncorhynchus masou at the Kumaishi station of the Hokkaido Fish Hatchery, Japan, have been reported, implying high mortality of fertilized eggs or failure of fertilization. In 2002, the average eyed-egg percentage and hatching rate of masu salmon at the Kumaishi station was $73.0 \%$ and $71.5 \%$, respectively, while it was $93.1 \%$ and 90.0\%, respectively, at the Mori station (N. Koide, pers. comm.), suggesting that some kind of environmental problem may have caused this difference. The aim of the present study was to determine if environmental stress caused the lowered eyed-egg percentage of pond-reared masu salmon at the Kumaishi station. First, serum cortisol levels of maturing masu salmon at the Kumaishi and Mori stations were measured and compared. Second, cortisol concentrations of serum and eyed eggs were measured and related to the eyed-egg percentage. Finally, the relationship between eyed-egg percentage and concentrations of $\mathrm{T}_{3}$ and $\mathrm{T}_{4}$ hormones in the eyed eggs was described.

\section{MATERIALS AND METHODS}

\section{EXPERIMENTAL FISH}

Masu salmon were reared in outdoor tanks under natural photoperiod with a continuous flow of spring water at the Kumaishi and Mori stations of the Hokkaido Fish Hatchery. The fish sampled at the Kumaishi and Mori stations originated in the Shiribetsu River and had been reared in intensive culture ponds for 20 and 35 years, respectively. The two stations belong in a similar agro-ecological zone. At the Mori and Kumaishi stations the 
average water temperature was $10.5 \pm 0.8^{\circ} \mathrm{C}$ and $9.0 \pm 0.9^{\circ} \mathrm{C}$, respectively, and a relatively high temperature fluctuation was observed at the Kumaishi station. The two stations have almost the same natural photoperiod, but there is no available data on water quality or turbidity at the two stations. Masu salmon at the Mori and Kumaishi stations start spawning at the beginning and in the middle of September, respectively.

Fish were fed dry pellets (Oriental Feed Industry, Yokohama, Japan) at the rate of $1.7-2.0 \%$ of body weight every two days until the end of July, after which they were not readily fed. Groups of 20 fish were sampled from March to September 2001 every two months. They were anaesthetized with tricaine methanesulfonate $\left(0.1 \mathrm{~g} \mathrm{l}^{-1}\right.$ MS222, Nakalai Tesque, Kyoto, Japan) and buffered with an equal amount of sodium bicarbonate. To minimize the effects of handling stress, blood was collected within 3 min of handling from the caudal vessels, kept on ice and later centrifuged at $1000 \mathrm{~g}$ for $10 \mathrm{~min}$ at $4^{\circ} \mathrm{C}$ to obtain serum samples, which were stored at $-30^{\circ} \mathrm{C}$ until assay.

For the investigation of cortisol concentrations of serum and eyed eggs in relation to the eyed-egg percentage, blood samples were collected from 33 mature female masu salmon at Kumaishi in September 2002. Sperm was pooled from mature males and 33 mature females' eggs were taken, kept separate by individual female, and artificially fertilized with the pooled sperm. The fertilized eggs were sampled at the eyed egg stage. Numbers of eyed and dead eggs were counted. In this study, fertilized eggs in which the embryo develops into the stage where eyes are clearly visible in the developing egg are called “eyed eggs”. Eyed-egg percentage (100 x total number of eyed eggs (total number of fertilized eggs) ${ }^{-1}$ ) was calculated for all eggs fertilized. The sampled fertilized eggs were stored at $-80^{\circ} \mathrm{C}$ for later extraction and hormonal analysis. 


\section{CORTISOL EXTRACTION FROM EYED EGGS}

Extraction of eyed eggs for cortisol measurement was done according to the method adopted by Hiroi et al. (1997). In brief, frozen eyed eggs weighing 100-200 mg were homogenized in a five-fold volume of ice-cold phosphate buffered saline (PBS). A total of $300 \mu \mathrm{l}$ of the homogenate was extracted twice with $3 \mathrm{ml}$ of diethyl ether by mixing vigorously for $2 \mathrm{~min}$. After freezing at $-80^{\circ} \mathrm{C}$ for $10 \mathrm{~min}$, the ether layer was collected by decantation and dried out at room temperature. To reconstitute the dried residue, $300 \mu \mathrm{l}$ of tetrachloromethane was added and mixed for 4 min. Then, $300 \mu \mathrm{l}$ of assay buffer was added and mixed for $2 \mathrm{~min}$. Finally, it was centrifuged at $1000 \mathrm{~g}$ for $10 \mathrm{~min}$ at $4^{\circ} \mathrm{C}$, and the upper layer was collected and stored at $-30^{\circ} \mathrm{C}$ for cortisol analysis.

\section{CORTISOL ASSAY}

Cortisol levels of serum and eyed eggs were measured using DELFIA Cortisol kit R060101 (Wallac Oy Turku, Finland) in a time-resolved fluorometer. A total of $25 \mu$ l of standard in triplicate and samples in duplicate was pipetted into 96-well microtiter plates, and diluted Eu-tracer/antibody solution was added and incubated for $1 \mathrm{~h}$ at room temperature. After a stringent wash, enhancement solution was added, and the intensity of fluorescence from dissociated Eu was measured with a time-resolved fluorometer using DOS-based Multicalc software. The standard curve in each assay was plotted, and sample values were calculated.

\section{ASSAYS OF $\mathrm{T}_{3} \mathrm{AND} \mathrm{T}_{4}$}

The protocols for $T_{3}$ and $T_{4}$ assays followed those developed by Yamada et al. (1997). In 
brief, frozen eyed eggs weighing 100-200 mg were homogenized in a five-fold volume of ice-cold PBS, and $300 \mu \mathrm{l}$ of the homogenates were used for $\mathrm{T}_{3}$ and $\mathrm{T}_{4}$ assays. Antisera for $T_{3}$ and $T_{4}$ were immobilized at the surface of the microtiter plates by physical adsorption for $18 \mathrm{~h}$ at $4^{\circ} \mathrm{C}$. Antisera, antibodies and europium-labeled thyroid BSA were kindly provided by Dr. H. Yamada, Kitasato University. Then, $50 \mu$ l of assay buffer, $60 \mu \mathrm{l}$ standards and $10 \mu \mathrm{l}$ of samples were added. Next, $50 \mu \mathrm{l}$ of europium thyroid BSA (Eu$\mathrm{T}_{3}$-BSA and Eu- $\mathrm{T}_{4}$-BSA) in assay buffer was added to the plates. Finally, $50 \mu \mathrm{l}$ of anti- $\mathrm{T}_{3}$ and $-\mathrm{T}_{4}$ were dispensed and incubated overnight at $4^{\circ} \mathrm{C}$. After three washes with $0.9 \%$ saline, Eu was dissociated from the antibody-antigen complex on the surface of the wells with enhancement solution. The intensity of the dissociated Eu was measured by a timeresolved fluorometer.

\section{STATISTICAL ANALYSIS}

To assess differences in cortisol levels of male and female masu salmon at the Kumaishi and Mori stations, two-way ANOVA, followed by Bonferroni Post-test, was used. The relationships between eyed-egg percentages and cortisol levels, and eyed-egg percentages and thyroid hormone levels were examined using linear regression analysis. Statistics and graphing were performed using GraphPad Prism 4.0 (San Diego, CA, USA).

\section{RESULTS}

\section{COMPARISON OF SERUM CORTISOL LEVELS}

Serum cortisol levels were significantly higher in May and July for males at Kumaishi, but lower in September [Fig. 1(a)]. Serum cortisol levels of females in May and July 
were significantly higher (Two-way ANOVA, $n=10$, P $<0.01$ ) at Kumaishi than at Mori, but the levels at Kumaishi decreased in September [Fig. 1(b)].

EYED-EGG PERCENTAGES AND CORTISOL LEVELS IN SERUM AND EYED EGGS AT THE KUMAISHI STATION

The eyed-egg percentage decreased with increasing cortisol levels in both the maternal serum $\left(\mathrm{r}^{2}=0.689, n=33, \mathrm{P}<0.0001\right)$ [Fig. 2(a)] and eyed eggs $\left(\mathrm{r}^{2}=0.760, n=33, \mathrm{P}<\right.$ 0.0001) [Fig. 2(b)], indicating an inverse relationship. There was a linear positive relationship ( $\left.\mathrm{r}^{2}=0.647, n=33, \mathrm{P}<0.0001\right)$ between serum cortisol and fertilized eggs cortisol (data not shown). In contrast, as $\mathrm{T}_{3}\left(\mathrm{r}^{2}=0.484, n=33, \mathrm{P}<0.0001\right)$ [Fig. 3(a)] and $\mathrm{T}_{4}\left(\mathrm{r}^{2}=0.564, n=33, \mathrm{P}<0.0001\right)$ [Fig. 3(b)] levels increased in the eyed eggs, the eyed-egg percentage increased, indicating a positive relationship.

\section{DISCUSSION}

Assessment of the cortisol hormone levels during the gonadal maturation period of masu salmon at the Kumaishi and Mori stations indicated that serum cortisol levels of male masu salmon were much higher at Kumaishi (reaching approximately 11-14 times) than at Mori in May and July. Serum cortisol levels of female masu salmon were also very much higher at Kumaishi than at Mori in May (approximately 24 times), and slightly higher at Kumaishi (approximately 3 times) than at Mori in March, July and September. These results indicate that serum cortisol levels were typically high at Kumaishi when compared to Mori. The high serum cortisol levels observed in masu salmon at Kumaishi during the pre-spawning period may indicate a cumulative corticosteroid response to the 
environmental stressors through the activation of the hypothalamus-pituitary-interrenal axis (Rivier \& Rivest, 1991). Kubokawa et al. (1999) reported that male sockeye salmon Oncorhynchus nerka respond to confinement stress with elevated levels of cortisol during the breeding season. The exact source of the environmental stressor responsible for the increased cortisol levels of masu salmon at Kumaishi station is not known. It may be due to the frequent management practices that occurred in the rearing environment or the genetic variation that might arise from long-term rearing. As the problem occurred recently, the cause for low eyed-egg percentage at Kumaishi may be due to the environmental stress. However, the genetic variability that might generate from long-term rearing of these stocks could be not ruled out.

The simultaneous increase of cortisol levels in serum and eyed eggs in this study is consistent with previous reports. Intra-arterial injection of labeled cortisol in Pacific salmon has been shown to cause a transfer of cortisol to almost all tissues very shortly after application (Donaldson \& Fagerlund, 1972). Stratholt et al. (1997) indicated that increase plasma cortisol caused by an applied stressor leads to increased deposition of cortisol in the oocytes in adult female coho salmon, but they also suggested that the deposited egg cortisol content does not seem to affect early development. Besides, the entry of cortisol into the oocytes is suggested to be nonspecific by in vitro incubation of oocytes with labeled cortisol (Tagawa et al., 2000).

Cortisol levels in serum and eyed eggs were both negatively related to eyed-egg percentage. It is known that many factors are involved in raising serum cortisol levels in teleosts, and the high cortisol observed in this study might have caused the lowered eyedegg percentage in the pond-reared masu salmon at Kumaishi. With regard to this 
phenomenon, Campbell et al. (1992) reported that a direct application of an environmental stressor to maturing male or female salmonids during oogenesis could adversely affect the quality of gametes in terms of subsequent viability. They found that there were no differences in somatic weight or length between the repeatedly stressed and control groups at the end of the experiment, but exposure to repeated acute stress during reproductive development resulted in a significant delay in ovulation and reduced egg size in females, significantly lower sperm counts in males, and most importantly, significantly lower survival rates for progeny from stressed fish. Reproductive performance impairment has been reported in male stripped bass subjected to significant stress during maturation and spawning (Castranova et al., 2005). In addition, elevated plasma cortisol in juvenile and adult salmonids has also been associated with reduced immunocompetence, increased mortality rates, and decreased egg size and quality (Fevolden et al., 1993). Moreover, experiments in other mammals (guinea pigs and mice) indicate that a stress response in the mother, such as elevated levels of catecholamines and corticosteroids, can be reflected in the fetus and may cause alterations to the developing offspring (Dauprat et al., 1990; Takahashi et al., 1998). Assuming the cortisol in the fertilized eggs to be of maternal origin and considering the highly variable nature of serum cortisol in response to the presence or absence of stressors, it is possible to speculate that increases in serum cortisol in an adult fish caused by environmental stressors during gonadal development and maturation might result in an increase in cortisol levels in the ovulated, fertilized and eyed eggs. Thus, the increased cortisol might have deleterious effects on fertilized eggs and the future survival of the embryos at the Kumaishi station as cortisol is the hormone produced in response to the stress. 
When the $T_{3}$ and $T_{4}$ levels increased in eyed eggs, the eyed-egg percentages also increased, suggesting that fertilized eggs with higher eyed-egg percentages had higher $\mathrm{T}_{3}$ and $\mathrm{T}_{4}$ levels. Ayson \& Lam (1993) found that $\mathrm{T}_{4}$ injection of female rabbitfish Siganus guttatus caused $\mathrm{T}_{4}$ and $\mathrm{T}_{3}$ levels to increase in the females, and subsequently, to increase in their oocytes. The key role of these hormones appears to be associated with metamorphosis or direct development as supplementation of water or larval feed with thyroid hormones accelerates growth and developmental changes associated with the transition of teleost larvae to juveniles (Lam, 1980; Brown, 1997). The inhibition of thyroid hormone synthesis prevents the transition of larvae to juveniles in zebrafish Brachydanio rerio (Brown, 1997).

To summarize, the relationship between eyed-egg percentages and cortisol levels of serum and eyed eggs was revealed for the first time in masu salmon at the Kumaishi station. The high cortisol levels observed in serum and fertilized eggs may cause a lowered eyed-egg percentage at this station. Since many of the management practices used in hatcheries can be potentially stressful, quantitative evaluation of the effects of such procedures on gamete quality could facilitate changes in the conditions employed so that stress is minimized and production of valuable offspring is ensured. Thus, it is relevant to try to consider and clarify such relationships in other teleosts and use this information for better management of hatcheries.

This work was supported in part by grant Numbers JSPS-RFTF 97L00901 from the "Research for Future Program" of the Japan Society for the Promotion of Science (JSPS), a grant from the River Front Foundation, and a grant from the Mitsubishi Foundation. 
The authors thank Dr. H. Yamada, Kitasato University for kindly providing BSAconjugated antigens and antibodies for TR-FIA, and Dr. M. Tagawa, Kyoto University for sending the egg extraction manual for cortisol assay. Special thanks are due to Dr. Jill B.K. Leonard, Northern Michigan University for critically reading the manuscript.

\section{REFERENCES}

Acerete, L., Balasch, J.C., Espinosa, E., Josa, A. \& Tort, L. (2004). Physiological responses in Eurasian perch (Perca fluviatilis, L.) subjected to stress by transport and handling. Aquaculture 237, 167-178.

Ayson, F.G. \& Lam, T.J. (1993). Thyroxine injection of female rabbitfish Siganus guttatus broodstock: changes in thyroid hormone levels in plasma, eggs, and yolksac larvae, and its effect on larval growth and survival. Aquaculture 109, 83-93.

Bromage, N., Jones, J., Randall, C., Thrush, M., Springate, J., Duston, J. \& Barker, G. (1992). Broodstock management, fecundity, egg quality and the timing of egg production in the rainbow trout Oncorhynchus mykiss. Aquaculture 100, 141-166.

Brown, D.D. (1997). The role of thyroid hormone in early development in zebrafish. Proceedings of the National Academy of Sciences USA 94, 13011-16.

Campbell, P.M., Pottinger, T.G. \& Sumpter, J.P. (1992). Stress reduces the quality of gametes produced by rainbow trout. Biology of Reproduction 47, 1140-1150.

Castranova, D.A., King V, W. \& Woods Ш, C. (2005). The effect of stress on androgen production, spermiation response and sperm quality in high and low stress responsive domesticated male striped bass. Aquaculture 246, 413-422.

Dauprat, P., Dalle, M. \& Delost, P. (1990). Effects of neurotrophic stress on maternal 
metabolism and binding of plasma cortisol in late pregnant guinea pigs and their fetuses. Journal of Developmental Physiology 13, 13-16.

Davis, C.R., Okihiro, M.S. \& Hinton, D.E. (2002). Effects of husbandry practices, gender, and physiological variation on growth and reproduction of Japanese medaka Oryzias latipes. Aquatic Toxicology 60 (3-4), 185-201.

Davis, K.B., Griffin, B.R. \& Gray, W.L. (2002). Effect of handling stress on susceptibility of channel catfish Ictalurus panctatus to Icthyopthirius multifullis and channel catfish virus. Aquaculture 214, 55-66.

Deane, E.E. \& Woo, N.Y.S. (2003). Ontogeny of thyroid hormones, cortisol, hsp70 and hsp90 during silver sea bream larval development. Life Sciences 72, 805-818.

Donaldson, E.M. \& Fagerlund, U.H.M. (1972). Corticosteroid dynamics in Pacific salmon. General and Comparative Endocrinology 3, 254-265.

Fernandez-Palacios, H., Izquierdo, M., Robaina, L., Valencia, A., Salhi, M. \& Montero, D. (1997). The effect of dietary protein and lipid from squid and fish meals on egg quality of broodstock for gilthead seabream Sparus aurata. Aquaculture 148, 233246.

Fevolden, S.E., Nordmo, R., Refstie, T. \& Roed, K.H. (1993). Disease resistance in Atlantic salmon (Salmo salar) selected for high or low response to stress. Aquaculture 109, 215-224.

Foo, J.T.W. \& Lam, T.J. (1993a). Serum cortisol response to handling stress and the effect of cortisol implantation on testosterone level in the tilapia Oreochromis mossambicus. Aquaculture 115, 145-158.

Harris, J. \& Bird, D.J. (2000). Modulation of the fish immune system by hormones. 
Veterinary Immunology and Immunopathology 77, 163-176.

Hiroi, J., Sakakura, Y., Tagawa, M., Seikai, T. \& Tanaka, M. (1997). Developmental changes in low-salinity tolerance and responses of prolactin, cortisol and thyroid hormones to low-salinity environment in larvae and juveniles of Japanese flounder (Paralichthys olivaceus). Zoological Science 14, 987-992.

Kime, D.E. \& Nash, J.P. (1999). Gamete quality as an indicator of reproductive endocrine disruption in fish. The Science of the Total Environment 223, 123-129.

Kjorsvik, E. (1994). Egg quality in wild and broodstock cod Gadus morhua L. Journal of World Aquaculture Society 25, 22-29.

Kubokawa, K., Watanabe, T., Yoshioka, M. \& Iwata, M. (1999). Effects of acute stress on plasma cortisol, sex steroid hormone and glucose levels in male and female sockeye salmon during the breeding season. Aquaculture 172, 335-349.

Lam, T.J. (1980). Thyroxine enhances larval development and survival in tilapia Sarotherodon mossambicus Ruppell. Aquaculture 21, 287-91.

Leatherland, J.F. (1982). Environmental physiology of the teleostean thyroid gland: a review. Environmental Biology of Fishes 7, 83-110.

Rivier, C. \& Rivest, S. (1991). Effects of stress on the activity of the hypothalamicpituitary-gonadal axis: peripheral and central mechanisms. Biology of Reproduction 45, 523-532.

Schreck, C.B., Contreras-Sanchez, W. \& Fitzpatrick, M.S. (2001). Effects of stress on fish reproduction, gamete quality, and progeny. Aquaculture 197, 3-24.

Stratholt, M.L., Donaldson, E.M. \& Liley, N.R. (1997). Stress induced elevation of plasma cortisol in adult female coho salmon (Oncorhynchus kisutch), is reflected 
in egg cortisol content, but does not appear to affect early development. Aquaculture 158, 141-153.

Tagawa, M., Tanaka, M., Matsumoto, S. \& Hirano, T. (1990). Thyroid hormones in eggs of various freshwater, marine and diadromous teleosts and their changes during egg development. Fish Physiology and Biochemistry 8, 515-20.

Tagawa, M., Suzuki, K. \& Specker, J.L. (2000). Incorporation and metabolism of cortisol in oocytes of Tilapia (Oreochromis mossambicus). Journal of Experimental Zoology 287, 485-492.

Takahashi, L.K., Turner, J.G. \& Kalin, N.H. (1998). Prolonged stress-induced elevation in plasma corticosterone during pregnancy in the rat: implications for prenatal stress studies. Psychoneuroendocrinology 23, 571-581. 


\section{FIGURE CAPTIONS}

Fig. 1. Comparison of serum cortisol levels of male (a) and female (b) maturing masu salmon from March to September 2001 at the Kumaishi and Mori stations. Cortisol levels for Kumaishi are represented by open circle and dashed lines (o) and for Mori by solid circle and lines $(\bullet)$. Values represent the mean \pm S.E. $(n=$ 10). Asterisks indicate significant difference between the two stations. ${ }^{*} \mathrm{P}<0.05$; $* * \mathrm{P}<0.01$.

Fig. 2. Relationship between eyed-egg percentage; and serum (a) and eyed eggs (b) cortisol levels in female masu salmon at the Kumaishi station $(n=33)$.

Fig. 3. Relationship between eyed-egg percentage; and $T_{3}(a)$ and $T_{4}$ (b) levels of eyed eggs in female masu salmon at the Kumaishi station $(n=33)$. 

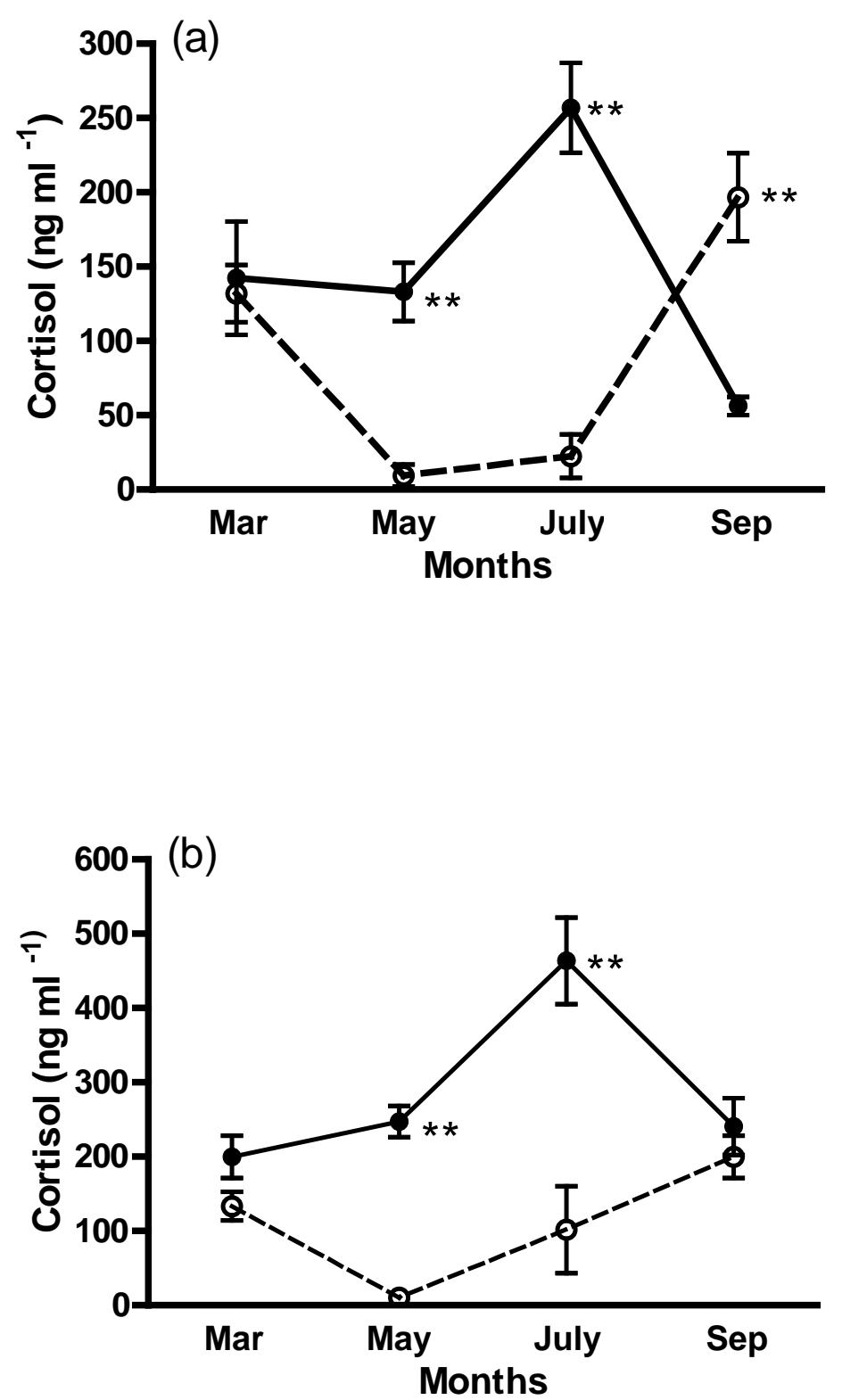

Fig. 1 

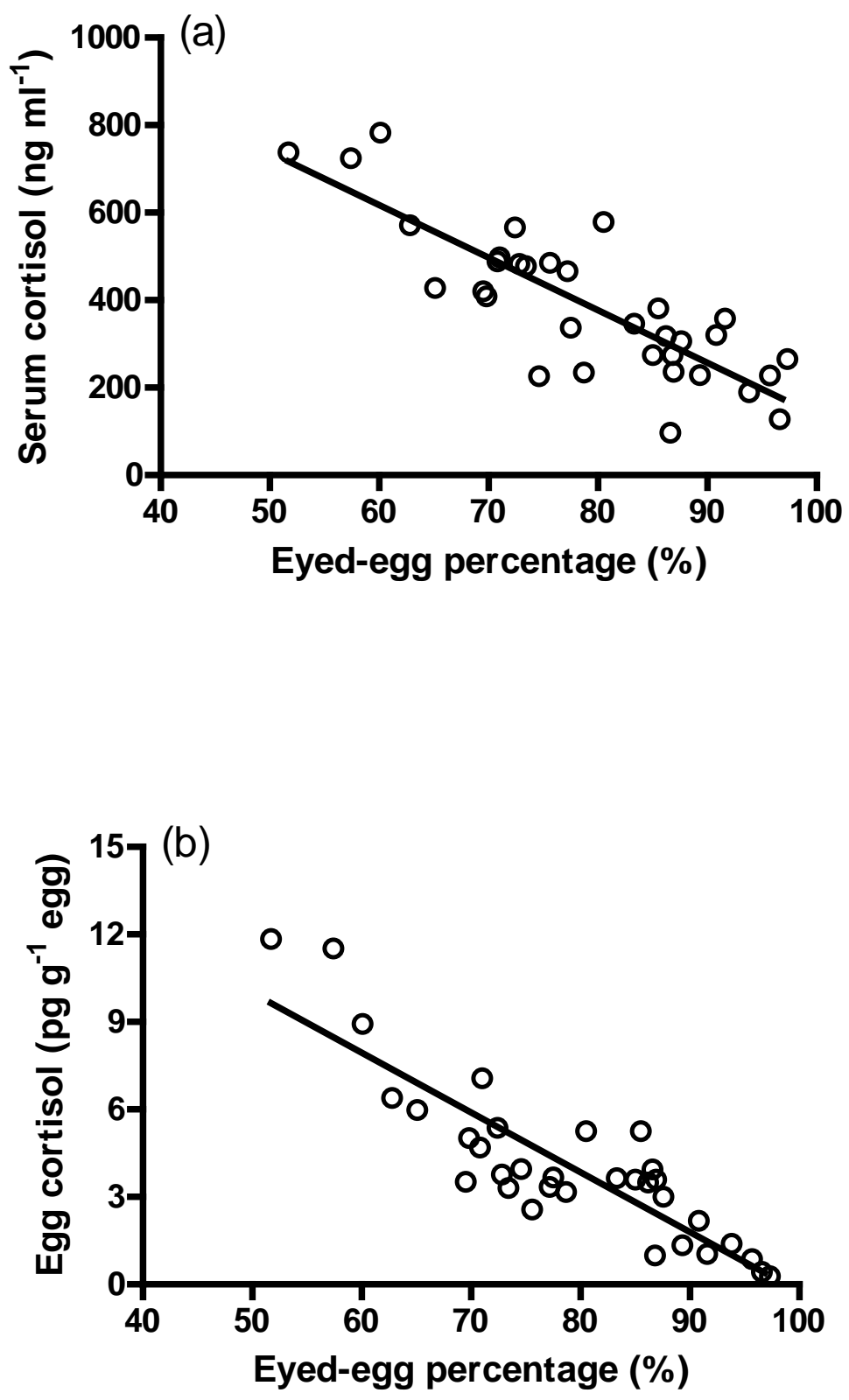

Fig. 2 

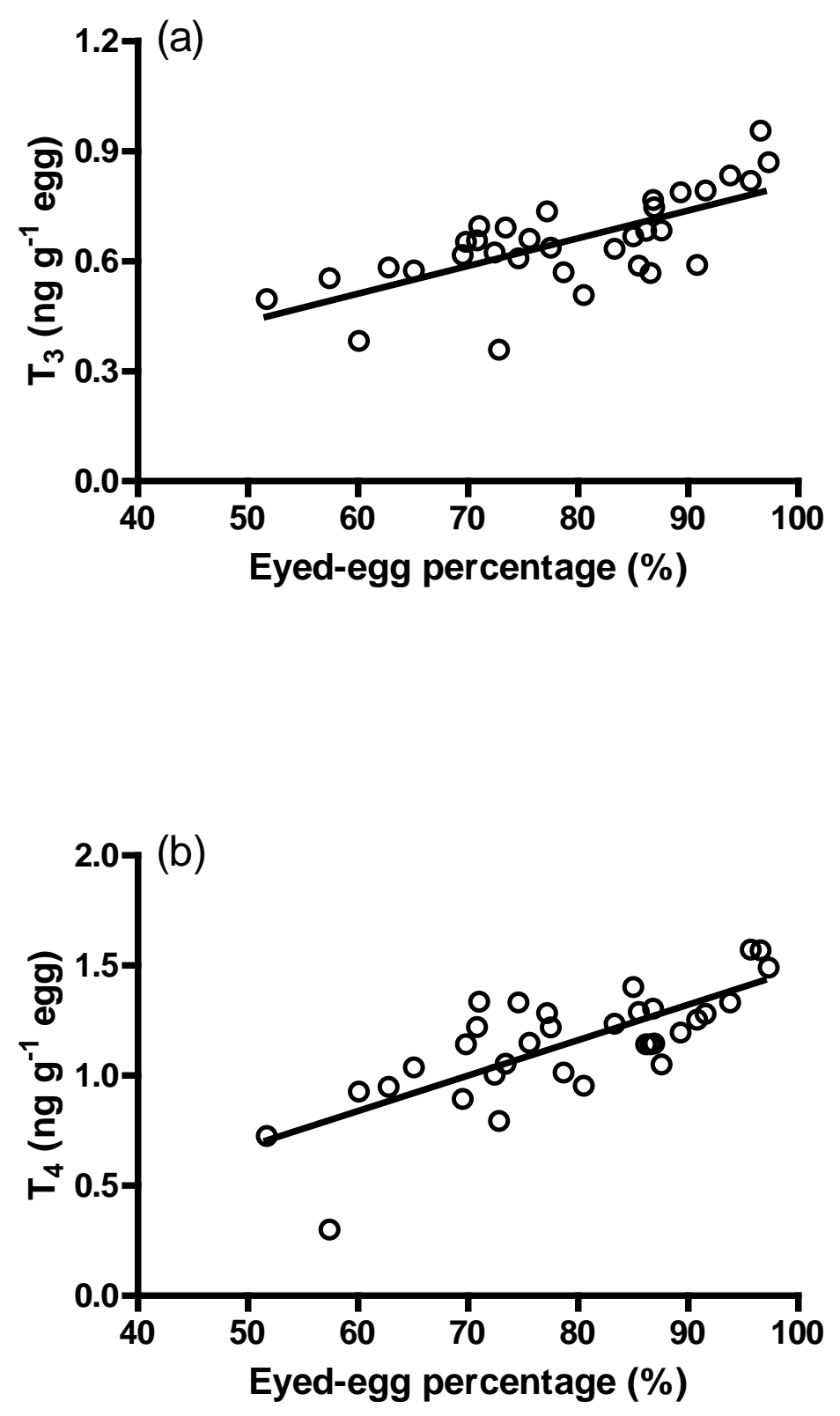

Fig. 3 